\title{
Ancient DNA extraction from bones and teeth
}

\author{
Nadin Rohland \& Michael Hofreiter \\ Max Planck Institute for Evolutionary Anthropology, Deutscher Platz 6, D-04103 Leipzig, Germany. Correspondence should be addressed to N.R. (rohland@eva.mpg.de).
}

Published online 12 July 2007; doi:10.1038/nprot.2007.247

\begin{abstract}
This method is designed to maximize recovery of PCR-amplifiable DNA from ancient bone and teeth specimens and at the same time to minimize co-extraction of substances that inhibit PCR. This is achieved by a combination of DNA extraction from bone powder using a buffer consisting solely of EDTA and proteinase $K$, and purification of the DNA by binding to silica in the presence of high concentrations of guanidinium thiocyanate. All steps are performed at room temperature $\left(20-23{ }^{\circ} \mathrm{C}\right)$, thereby reducing further degradation of the already damaged and fragile ancient DNA and providing an optimal trade-off between DNA release and degradation. Furthermore, the purification step removes most of the various types of PCR inhibitors present in ancient bone samples, thereby optimizing the amount of ancient DNA available for subsequent enzymatic manipulation, such as PCR amplification. The protocol presented here allows DNA extraction from ancient bone and teeth with a minimum of working steps and equipment and yields DNA extracts within 2 working days.
\end{abstract}

\section{INTRODUCTION}

Rationale

Since its beginning, research on ancient DNA has suffered from the problem that, in almost all ancient specimens, any DNA that is preserved is present only in small amounts and in various states of degradation. Therefore, it is crucial to make this DNA available as much as possible for further enzymatic manipulation. This usually involves amplification by PCR, but more recent approaches also include ligation into bacterial vectors ${ }^{1,2}$ or addition of oligonucleotides for direct sequencing ${ }^{3-5}$. However, this is not a trivial task. First, most DNA extraction methods are designed to deal with fresh tissue containing intact cells and high molecular weight DNA. In ancient specimens, usually no cell structures are preserved (but see ref. 6 for rare exceptions) and, owing to as yet uncharacterized chemical modifications, it may even be difficult to get the DNA into aqueous solution ${ }^{7}$. Second, ancient DNA is damaged in various ways $^{8-11}$, so extraction methods also have to avoid overly aggressive treatments, such as high temperatures or use of strong detergents ${ }^{12}$. Although these treatments might increase DNA release, they would decrease overall DNA yield by inflicting further damage to the ancient DNA molecules. Third, ancient bones and teeth often contain large amounts of PCR inhibitors ${ }^{13-15}$ that interfere with DNA amplification and are co-purified with ancient DNA. Thus, ancient DNA extraction methods have to deal with a number of problems that are sometimes difficult to reconcile. The method described here is the result of testing, on a number of Pleistocene samples, a wide range of conditions and ingredients from one published method ${ }^{16}$, followed by a final comparison of the optimized procedure to other published ancient DNA extraction methods ${ }^{12}$. It provides a trade-off between DNA release, DNA degradation during extraction and separation of DNA and inhibitors, thereby maximizing the DNA available for further applications. We have applied it successfully to extractions from bone and teeth samples originating from both cave ${ }^{12}$ and open sites ${ }^{17}$, from permafrost $^{17}$ as well as non-permafrost environments ${ }^{12}$, and with sample sizes ranging from less than $50 \mathrm{mg}$ (unpublished) to $40 \mathrm{~g}$ of bone powder if a concentration step is included ${ }^{1,17}$.

As is generally the case when working with ancient DNA, a number of precautions have to be taken during extraction of ancient specimens; these have been extensively described elsewhere ${ }^{18-21}$.
Advantages of silica extraction over other ancient DNA extraction methods

Several methods for ancient DNA extraction exist, including ethanol or isopropanol precipitation ${ }^{14,15}$, concentration of DNA using membranes ${ }^{22}$ and binding DNA to silica ${ }^{16}$. Compared to these extraction methods, the improved silica method described here has several advantages.

(1) Quick and easy: this is a relatively fast method; it yields ancient DNA extracts within 2 working days and involves only a limited workload.

(2) Scalable: the protocol can easily be adapted to different amounts of bone powder and extraction volumes. We have used it for extractions ranging from as little as $50 \mathrm{mg}$ bone powder in $1 \mathrm{ml}$ extraction solution (unpublished) to $2 \mathrm{~g}$ of bone powder in $10 \mathrm{ml}$ extraction solution (unpublished). If a concentration step ${ }^{1,17}$ is included between extraction and purification of DNA, up to $40 \mathrm{~g}$ of bone powder in 1 liter of extraction solution can easily be processed.

(3) Simple to implement: the method requires only standard laboratory equipment and a small number of chemicals and is processed at room temperature $\left(20-23{ }^{\circ} \mathrm{C}\right)$. It can therefore be established rapidly.

(4) Efficient removal of PCR inhibitors: we found this method to efficiently separate ancient DNA and PCR inhibitors ${ }^{12}$, a crucial problem in ancient DNA research ${ }^{13-15}$.

In fact, in a comparison with published methods, we found this protocol on average to yield the highest values of amplifiable DNA when tested on a number of Pleistocene cave bear samples $^{12}$. This is not to claim that for certain samples, other protocols may not yield better results. However, given its superior performance on average and in the absence of prior knowledge of which method works best on a particular sample, this method can be seen as the most promising extraction method to start with for ancient samples. Moreover, its average high performance offers the greatest chance of success in analyses of large numbers of specimens ${ }^{23,24}$, where it is impractical to test various extraction methods on each sample, or when the value of a sample allows only one extraction, for example, in the case of Neanderthal samples ${ }^{25-27}$. 


\section{Other potential applications of this method}

We have tested the method on a number of Pleistocene samples ${ }^{12,17}$ and on samples from various types of fossil sites (e.g., caves ${ }^{12}$, open sites (unpublished) and permafrost environments ${ }^{17}$ ). So far, our experience has been positive; results have even been obtained from samples that had failed previously. We have also been able to amplify nuclear genes ${ }^{17}$ from extracts obtained using this method. Thus, we would recommend this protocol for extracting DNA from bone and teeth samples of any age, including museum specimens, historical samples and even modern bone. However, it should be noted that other methods ${ }^{22,28,29}$ may yield better results with other types of samples, such as museum specimens, especially if they have been treated for storage $e^{30}$.

\section{Optimization of the method}

If unsatisfactory results are obtained for a certain type of sample, the extraction solution can be adjusted to the attributes of the sample type. Reducing agents (e.g., $50 \mathrm{mM}$ dithiothreitol) and detergents (e.g., $1 \%(\mathrm{v} / \mathrm{v})$ Triton $\mathrm{X}-100)$ can be added to the extraction solution to destroy proteins and intact cell membranes if modern or historical bones or teeth are extracted. $N$-phenacylthiazolium bromide (PTB) can be added to cleave Maillard products (sugar-derived protein crosslinks, e.g., in feces samples) ${ }^{31}$. Alternatively, other extraction methods ${ }^{14,15,22,29}$ may be evaluated.

For samples that do not contain PCR inhibitors, salts other than guanidinium thiocyanate (GuSCN) may be used, for example sodium chloride ${ }^{12}$. These non-chaotropic salts are much cheaper and perform equally well or even better in terms of DNA recovery. However, they tend to co-purify PCR inhibitors and therefore should not be used for samples that are likely to contain PCR inhibitors.

\section{Limitations of this extraction method}

A clear advantage of this method is its broad applicability to bone and teeth samples and the relatively short time necessary for obtaining DNA extracts. However, a limitation lies in the fact that it is specific to bone and teeth samples; this is due to the high amounts of EDTA in the extraction solution, which is necessary to dissolve part of the hydroxylapatite matrix specific to bone and teeth samples. The method may well be adapted to other types of samples by changing the extraction solution; for example, the addition of PTB has been shown to help DNA release from feces samples, possibly by releasing DNA from DNA-protein cross- links ${ }^{31}$; the use of detergents and reducing agents is generally recommended when processing fresh samples where intact proteins and/or cells are present. Other ingredients may support DNA release from various sources (e.g., polyvinylpyrrolidone for plants $\left.{ }^{32}\right)$; however, this has not been tested comprehensively. Finally, reducing the concentration of EDTA for samples other than bones and teeth, or addition of Tris- $\mathrm{HCl}$ to buffer the extraction solution may help when other source materials are used. However, it should be noted that none of these chemicals improved DNA yields from ancient bones and teeth ${ }^{12}$.

All the above suggested modifications will need careful evaluation and optimization for each type of sample (such as feces, soft tissues, plants or sediments), to yield optimal results. However, as the vast majority of sequences used in ancient DNA research are obtained from bone or teeth specimens, this shortcoming is of limited importance.

Another drawback of this extraction method is that not only endogenous DNA is extracted from the sample, but also bacterial and fungal DNA that accumulated on the sample owing to microorganisms living in the surrounding sediment, on the sample itself or that have been introduced during collection or storage of the samples. As shown many times, the amount of exogenous DNA usually exceeds the amount of endogenous DNA several fold (refs. 1, 5 and 9, but see ref. 4 for an example of high amounts of endogenous DNA). However, no method that overcomes this problem is currently available.

\section{General considerations}

This protocol (for an overview, see Fig. 1) is written for a sample amount of around $500 \mathrm{mg}$. If the amount of sample is smaller or larger, adjust the volume of extraction solution proportionally (Step 6). For DNA binding to silica (Step 10), use four times the volume of binding buffer compared to the volume of extraction solution. Add $100 \mu \mathrm{l}$ of silica suspension also for smaller amounts of sample/buffer, but do not add more silica if you exceed the recommended volumes mentioned here, as a proportion of the elution buffer will remain in the silica and the elution volume will fall below $50 \mu \mathrm{l}$. If you use more than $100 \mu \mathrm{l}$ silica suspension, increase the elution volume. Note that the amount of $\mathrm{HCl}$ required to adjust the $\mathrm{pH}$ (Step 10) will also need to be adjusted. All steps described in this procedure are performed at room temperature $\left(20-23{ }^{\circ} \mathrm{C}\right)$ if not stated otherwise.

\section{MATERIALS}

\section{REAGENTS}

- Sodium hypochlorite solution (10-13\%)—Bleach (Sigma, cat. no. 425044)

I CAUTION Alkaline, may cause skin irritation; wear protective clothes and gloves.

-Water, HPLC-grade (Sigma, cat. no. 270733)

- EDTA disodium salt dihydrate (Sigma, cat. no. E5134)

- Proteinase K (Sigma, cat. no. P6556)

- GuSCN (Sigma, cat. no. G9277) ! CAUTION Harmful; wear protective clothes and gloves.

- Tris(hydroxymethyl)aminomethane (Tris base) (Sigma, cat. no. T1503)

- Sodium chloride (Sigma, cat. no. S7653)

- Silicon dioxide (Sigma, cat. no. S5631) (see REAGENT SETUP)

- $\mathrm{HCl}$ (Fluka, cat. no. 17077) 30\% w/v ! CAUTION Acidic, may cause skin

irritation; wear protective clothes and gloves.

- Absolute ethanol (Merck, cat. no. 1.00983.2500)

- TE buffer, 10 mM Tris, 1 mM EDTA, pH 8.0

- Extraction solution (see REAGENT SETUP)
- Binding buffer (see REAGENT SETUP)

- Washing buffer (see REAGENT SETUP)

EQUIPMENT

- Two separate rooms with one hood in the first and two hoods (laminar flow hoods are recommended) in the second room; the minimum requirement is at least two hoods in one room to separate the dust-producing bone preparation from the buffer preparation, extraction procedure and setup of PCR, as these latter processes are very susceptible to contamination (see EQUIPMENT SETUP)

- Drilling/cutting equipment with exchangeable cutting blades, discs and/or drilling bits (e.g., MICROMOT 40/E from Proxxon, cat. no. NO28515, and grinding and cutting discs from Proxxon, cat. nos. NO28812 and NO28830) - Mortar and pestle (one set per sample) or alternatively a freezer mill (e.g., Spex 6770 freezer mill from Spex SamplePrep, cat. no. 6770-230) with accessories (cat. no. 6751) $\Delta$ CRITICAL A sufficient number of grinding vials are required to prepare more than one sample per day. Grinding vials need to be thoroughly cleaned before reuse (see EQUIPMENT SETUP). 
- Liquid nitrogen, if using a freezer mill ! CAUTION Wear protective clothes and gloves to prevent freeze burning.

- Rotary wheel, or similar equipment to keep the tubes agitated during incubation, with holders for different sized tubes (2-, 15- and 50-ml tubes)

- Two balances, one for chemicals and one for samples $\Delta$ CRITICAL To prevent contamination of chemicals with sample material, the balance for the chemicals must not be used for weighing the samples and vice versa.

- Table top centrifuges: one suitable for the use of 15- and 50-ml conical tubes with speed up to $5,000 \mathrm{~g}$ (e.g., Multifuge $3 \mathrm{~S}$ from Heraeus), another for 1.5- and 2-ml tubes with speed up to 16,000g (e.g., Microcentrifuge 5415D from Eppendorf)

- Filter tips are recommended to minimize the risk of cross-contamination owing to DNA aerosols.

- $\mathrm{pH}$ indicator strips (e.g., pH-Fix 3.6-6.1, Macherey-Nagel, art. no. 921 30)

-Standard laboratory equipment such as different sized tubes, freezer and refrigerator for storing extracts and chemicals.

REAGENT SETUP

TIMING $\mathbf{5} \mathbf{h}$ for preparation of silica suspension, 30-60 $\mathrm{min}$ for all other buffers

General considerations Prepare all buffers, solutions and suspensions with HPLC-grade water and use only disposable equipment to weigh chemicals and prepare buffers. To minimize the risk of contamination, never put chemicals back into the storage container. It has been shown ${ }^{33}$ that UV irradiation of PCR reagents reduces the amplification success by causing blocking lesions in the DNA strands. This 'decontamination' procedure could also be applied to UV-insensitive reagents, buffers, reaction tubes and surfaces to reduce the risk of contamination. For further details (recommended wavelengths and distance), see ref. 33.

Extraction solution $0.45 \mathrm{M}$ EDTA and $0.25 \mathrm{mg} \mathrm{m}^{-1}$ proteinase $\mathrm{K}$, $\mathrm{pH} 8.0$. A volume of $10 \mathrm{ml}$ is required per $500 \mathrm{mg}$ of sample. $\Delta$ CRITICAL Always prepare fresh and do not forget to include sufficient buffer volume for at least one negative control during each extraction to check for cross-contamination and reagent contamination; we recommend a minimum of one extraction control. For more than seven samples, two or more extraction controls should be included. Binding buffer $5 \mathrm{M} \mathrm{GuSCN}, 25 \mathrm{mM} \mathrm{NaCl}$ and $50 \mathrm{mM}$ Tris. Per sample $40 \mathrm{ml}$ are required plus $1 \mathrm{ml}$ per sample for the first washing step (Step 13). $\Delta$ CRITICAL If possible, prepare fresh; however, it can be used for a maximum of 3 weeks if stored in the dark at room temperature $\left(20-23{ }^{\circ} \mathrm{C}\right)$.

Washing buffer $50 \% \mathrm{v} / \mathrm{v}$ ethanol, $125 \mathrm{mM} \mathrm{NaCl}, 10 \mathrm{mM}$ Tris and $1 \mathrm{mM}$ EDTA, pH 8.0.

Preparation of silica suspension Suspend $4.8 \mathrm{~g}$ of silicon dioxide in water to a final volume of $40 \mathrm{ml}$ and leave to settle for $1 \mathrm{~h}$. Transfer $39 \mathrm{ml}$ of the supernatant to a new tube and allow to sediment for an additional $4 \mathrm{~h}$. Remove and discard $35 \mathrm{ml}$ of the supernatant and add $48 \mu \mathrm{lof} 30 \% \mathrm{w} / \mathrm{v} \mathrm{HCl}$ to the pellet. Aliquots (we recommend amounts of $850 \mu \mathrm{l}$ for extraction of seven samples and one blank control) should be stored at room temperature in the dark. $\triangle$ CRITICAL Silica suspension should be used within 1 month of preparation.

\section{EQUIPMENT SETUP}

Laboratory requirements Two rooms are necessary to safely separate the dust-producing working steps from the contamination-susceptible steps like buffer preparation and PCR setup. The first room is used for cutting and grinding the samples with appropriate equipment and disposables. The second room is used for preparation of buffers and setup of PCR reagent mix (first hood) and extraction of the samples and addition of DNA extract to the PCR (second hood). If only one room with two hoods is available, we would recommend separating the sample preparation from all other steps (buffer preparation, extraction procedure and PCR setup).

General considerations about handling The samples used for extraction will usually contain only trace amounts of DNA. To avoid cross-contamination among samples, all steps that do not involve handling of bone samples (such as preparation of buffers, labeling of tubes, etc.) should, as far as possible, be performed before manipulation of the samples. Equipment where a different set

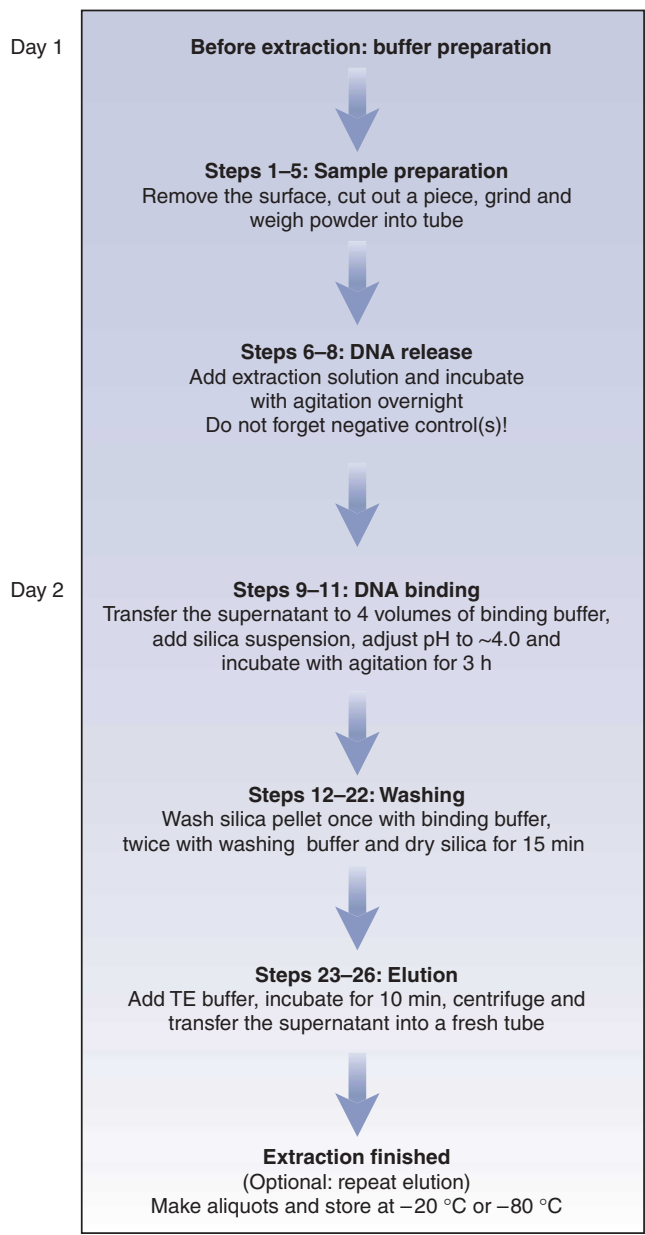

Figure 1 | Flow diagram for DNA extraction from ancient bones and teeth.

is used for each sample (such as mortar and pestle or cutting discs) should be stored in a way that makes it easily accessible but prevents contamination of later samples with dust from the earlier samples. Manipulation of each bone sample must be completed to the point where the amount of powder necessary for extraction has been weighed and placed in the extraction tube before commencing with the next sample. Additional powder, as well as the remaining bone sample, must be stored away safely to avoid cross-contamination between samples. Single-use equipment must be removed from the working area. Finally, the working area and equipment such as the drill bit have to be cleaned appropriately (e.g., with sodium hypochlorite solution followed by water or ethanol) before work on the next sample is started. Various ways of cleaning/ decontamination of equipment and work areas are possible. If no work is in progress, equipment and working area should be UV-irradiated ${ }^{33}$. Equipment should be first chemically cleaned (e.g., with sodium hypochlorite solution), followed by thorough removal of any potential DNA-damaging chemicals using water and/or ethanol. Finally, equipment should be UV-irradiated at least overnight. Care has to be taken with equipment that may be damaged by the treatment, such as metal equipment, which will be damaged by hypochlorite solution. In such cases, cleaning/decontamination can be done using water and UV irradiation.

\section{PROCEDURE}

\section{Preparation of the bone or tooth sample TIMING 15-30 min per sample}

1| Remove dirt from the surface of the specimen with a tissue. If necessary, moisten the tissue with HPLC-grade water. $\triangle$ CRITICAL STEP Dirt may introduce a variety of inhibitory substances to the extraction procedure, and therefore to the extract itself; these substances may interfere or even completely block subsequent enzymatic manipulations of the DNA extracts. 
2| Remove the outer surface of part of the specimen with a single-use grinding tool.

$\triangle$ CRITICAL STEP This step removes possible contamination introduced during excavation, storage or collection, or other investigations of the specimen; although no $100 \%$ efficient procedure to remove contamination exists ${ }^{34}$, this step may improve the ratio between endogenous and contaminating DNA; moreover, it may further reduce the amount of inhibitors introduced into the extraction.

3| Cut off or cut out a piece of the specimen (you may have to reconcile with curatory requirements to minimize physical damage); if possible, sample from a compact part of the bone. When using teeth, cut off the root or use a part of the dentine, for example from inside the root, depending on curatory requirements. Most curators may not allow a piece to be cut from the (often unique) specimen. An alternative is to drill inside the specimen to obtain a fine powder without the need of further grinding. Drill with low speed to prevent overheating, which would damage the DNA.

! CAUTION Be careful with sharp cutting discs.

$\triangle$ CRITICAL STEP It is assumed that DNA is better preserved in compact parts of the bone than in more spongiose parts; therefore, we recommend using compact parts of bones, for example, the diaphyses of long bones. Use dentine rather than enamel from teeth, as dentine is assumed to contain more DNA.

- PAUSE POINT The sample can be stored at room temperature (e.g., together with the original specimen).

$4 \mid$ Grind the sample intended for DNA extraction with a mortar and pestle until a fine-grained powder is obtained. If necessary (e.g., if the sample is very hard), use a freezer mill.

$\triangle$ CRITICAL STEP Try to obtain as fine a powder as possible; the finer the powder, the more DNA released ${ }^{12}$. However, if using a freezer mill or similar equipment, do not overgrind, as this may fragment the DNA.

5| Weigh out no more than $500 \mathrm{mg}$ of sample powder and transfer it to a $15 \mathrm{ml}$ tube.

PAUSE POINT The sample powder can be stored at room temperature, but should be subjected to the extraction as soon as possible.

\section{DNA release $\bigcirc$ TIMING 1 day (only 10 min work required)}

6| Add $10 \mathrm{ml}$ extraction solution to each $500-\mathrm{mg}$ sample powder. Also include a blank extraction (10 ml extraction solution without a sample); this has to be treated identically to the experimental samples throughout the procedure. It monitors for contamination of the chemicals or cross-contamination during the procedure.

$\triangle$ CRITICAL STEP A positive control should be included only if testing the protocol the first time, testing if new chemicals interfere with the protocol or if a previous extraction failed. If a positive control (of the same kind of material) is included, it is recommended that a different species is used to control for cross-contamination by testing both the blank extraction and all extracts for DNA from the positive control.

$\triangle$ CRITICAL STEP Use separate pipette tip for each sample to avoid cross-contamination.

7| Seal the capped tubes with Parafilm and incubate with gentle agitation (e.g., slow rotation) overnight ( $\sim 16-24 \mathrm{~h})$ in the dark.

8| Optional: Next day, to improve DNA yields, incubate with agitation for an additional $1-3 \mathrm{~h}$ at $56{ }^{\circ} \mathrm{C}$. This step improves the digestion of the bone powder and thereby releases more DNA, especially in cases when the powder used is relatively coarse.

If using a fine powder, this step can be omitted.

$\triangle$ CRITICAL STEP This step may cause further damage or degradation of the DNA owing to the high incubation temperature.

\section{DNA purification by binding to silica: preparation of DNA binding TIMING 30 min (for seven samples plus a negative control) \\ 9| Centrifuge the samples for 2 min at 5,000g.}

$\triangle$ CRITICAL STEP Keep the remaining sample material; you may wish to retain it for a second round of extraction, especially if working with rare samples.

10| Transfer the supernatant into $40 \mathrm{ml}$ binding buffer in a $50 \mathrm{ml}$ conical tube, add $100 \mu \mathrm{l}$ silica suspension and adjust the pH to $\sim 4.0$ by adding $\sim 300 \mu \mathrm{l}$ of $30 \% \mathrm{w} / \mathrm{v} \mathrm{HCl}$. First add only $200 \mu \mathrm{l}$ of $30 \% \mathrm{w} / \mathrm{v} \mathrm{HCl}$, mix gently and measure the pH by pipetting (this minimizes the chance of introducing contamination) a few microliters to indicator paper. If the $\mathrm{pH}$ is higher than 4.0, add more $\mathrm{HCl}$ in $25 \mu$ aliquots until $\mathrm{pH} 4.0$ is reached.

$\triangle$ CRITICAL STEP Silica needs to be vortexed before pipetting, as the particles settle down quickly.

$\triangle$ CRITICAL STEP The amount of HCl you need to add may vary from sample to sample, as the $\mathrm{pH}$ of the extraction solution depends on the amount and type of sample and the extent of decalcification (EDTA complexes calcium ions, thereby releasing hydrogen ions, and therefore influences the $\mathrm{pH}$ ).

$\triangle$ CRITICAL STEP Do not add too much $\mathrm{HCl}$ to the solution, as DNA will be destroyed at lower $\mathrm{pH}$ values. It is better to have a pH of 4.5 than 3.5.

! CAUTION HCl is acidic and may cause skin irritation; wear protective clothes and gloves. 


\section{DNA purification by binding to silica: incubation TIMING $3 \mathrm{~h}$ (no work required)}

11| Close the tubes and seal with Parafilm. Incubate with agitation for $3 \mathrm{~h}$ in the dark.

\section{DNA purification and elution TIMING 1-2 $\mathrm{h}$ (for seven samples plus a negative control)}

12| Centrifuge the samples for 2 min at $5,000 \mathrm{~g}$. Pour the supernatant into a new tube.

$\triangle$ CRITICAL STEP Keep the supernatant in the refrigerator until you know the extraction worked, otherwise you can repeat the binding step with the same binding buffer by adding new silica suspension.

13| Add $1 \mathrm{ml}$ binding buffer to the silica pellet and resuspend the silica by pipetting up and down.

14| Transfer the buffer-silica suspension into a fresh $2 \mathrm{ml}$ tube. This transfer makes handling more convenient, as $2 \mathrm{ml}$ tubes rather than $50 \mathrm{ml}$ tubes can be used in all following steps.

15| Centrifuge for $15 \mathrm{~s}$ at $16,000 \mathrm{~g}$.

16 Discard the supernatant and remove the remaining solution with a pipette.

$\triangle$ CRITICAL STEP If the binding solution is not completely removed, the salt concentration in the elution buffer will be too high and all DNA will not be released from the silica during elution.

17| Add $1 \mathrm{ml}$ washing buffer to the silica pellet and resuspend the silica by pipetting up and down.

18| Centrifuge for $15 \mathrm{~s}$ at $16,000 \mathrm{~g}$.

19| Discard the supernatant and remove the remaining liquid with a pipette.

20| Repeat Steps 17-19 once.

21| Centrifuge again for $15 \mathrm{~s}$ at $16,000 \mathrm{~g}$ and remove the remaining liquid with a pipette.

22| Dry the silica at room temperature for $\sim 15$ min with open lids.

23 Add $50 \mu \mathrm{l}$ TE buffer to the dried silica and resuspend by stirring with the pipette tip and pipetting up and down.

24| Incubate with closed lids for $\sim 10$ min; gently shake occasionally.

25| Centrifuge for 2 min at $16,000 \mathrm{~g}$.

26| Transfer the supernatant into a fresh tube. Optionally, the elution steps (Steps 23-26) can be repeated. Note that the second eluate will contain lower amounts of DNA compared to the first. Thus, combining both elutions will increase the total amount of DNA, but decrease the DNA concentration in the extract. It is also possible to store the first and second eluates separately, so that the first is not diluted by the second.

$\triangle$ CRITICAL STEP Try to avoid transferring large amounts of silica, as this may interfere with or even inhibit downstream applications.

\section{BOX 1 | METHODS FOR MEASURING DNA QUANTITY}

A number of approaches $(\mathrm{A}-\mathrm{C})$ can be used to determine the amount of DNA present in extracts of an ancient sample. A combination of methods $B$ and $C$ will also allow an approximate ratio of target to non-endogenous DNA to be estimated.

(A) Estimate DNA quantity and size distribution on an agarose gel

DNA quantity and size can be estimated by analyzing an aliquot by standard agarose gel electrophoresis ${ }^{35}$. The drawback of this method is that, because most of the DNA normally originates from other sources ${ }^{1}$, the results may be misleading. Also note that target DNA quantity in ancient DNA extracts may be very low and not visible on agarose gels; therefore dyes more sensitive than ethidium bromide, such as SYBR Green or SYBR Gold ${ }^{36}$, should be used for detection.

(B) Measure DNA concentration using a spectrophotometer

As above, a spectrophotometer (e.g., Nanodrop) measures not only endogenous DNA, but also contaminating DNA of bacterial or fungal origin, for example, which usually represents the vast majority of the sample. Measuring DNA concentration via absorption of UV light at $260 \mathrm{~nm}$ may not be sensitive enough; therefore, measurements using fluorescent dyes such as Pico Green, which binds to dsDNA and increases the fluorescent signal, and extrapolation via a standard curve are recommended ${ }^{37}$.

(C) Measure DNA quantity of the target species using quantitative PCR

Quantitative PCR ${ }^{38}$ will yield information only about the amount of DNA of a specific locus and fragment length; however, it can be extrapolated to the total DNA amount from the target species. 
27| Use this extract, or a dilution, for downstream applications. If necessary, determine the concentration of DNA in the extract as outlined in Box 1.

PAUSE POINT Store the extract at -20 or $-80{ }^{\circ} \mathrm{C}$. It is better to aliquot the DNA before freezing to avoid DNA loss during freeze-thaw cycles.

? TROUBLESHOOTING

\title{
TIMING
}

Silica preparation: $5 \mathrm{~h}$

Buffer preparation: $30-60$ min

Steps 1-5, preparation of the bone or tooth sample: $15-30$ min per sample

Steps 6-8, DNA release: 1 day (only 10 min work required)

Steps 9 and 10, DNA purification by binding to silica: preparation of DNA binding: $30 \mathrm{~min}$ (for seven samples plus a negative control)

Step 11, DNA purification by binding to silica: incubation: $3 \mathrm{~h}$ (no work required)

Steps 12-27, DNA purification and elution: 1-2 $\mathrm{h}$ (for seven samples plus a negative control)

\section{$?$ TROUBLESHOOTING}

Troubleshooting advice can be found in Table 1.

TABLE 1 | Troubleshooting table.

\begin{tabular}{ll}
\hline Problem & Possible reason \\
\hline Downstream appli- & Inhibitory substances \\
cation failed & co-extracted
\end{tabular}

\begin{abstract}
Solution
Include a positive control to confirm that the procedure worked and to determine whether the samples were inhibited

Use a dilution of the extract or spike-clean DNA with extract to clarify whether the extract is inhibitory; for the spiking experiment, add the possibly inhibitory extract to a working reaction and check if the reaction is still working or not. If not, your extract is inhibitory Use more enzyme (e.g., Taq DNA polymerase for PCR)

Repeat the extraction with smaller amounts of sample powder

Include a positive control to confirm that the procedure worked

Spike-clean DNA with extract to make sure the extract is not inhibitory

Use more extract in the downstream application

Repeat the extraction with more sample material: take more than the recommended amount of sample powder (at least twice as much), incubate in an appropriate amount of extraction solution. Split the supernatant in several aliquots of $10 \mathrm{ml}$ each, add the first $10 \mathrm{ml}$ aliquot to the recommended binding buffer plus silica and incubate for $3 \mathrm{~h}$. Centrifuge and discard supernatant. Add the next $10 \mathrm{ml}$ extraction supernatant plus $40 \mathrm{ml}$ binding buffer to the very same silica pellet and again incubate for $3 \mathrm{~h}$. Repeat this binding step until all the extraction supernatant is processed. Complete the protocol as recommended (Steps 12-27) Repeat the binding step in the original binding buffer from Step 12, add new silica and adjust the $\mathrm{pH}$ again; if the $\mathrm{pH}$ was too low, the DNA will have degraded and you need to start from the beginning

Prepare new reagents
\end{abstract}

Sample contains little or no DNA

Binding to silica was inefficient

Solutions, buffers and/or silica too old

Extraction control is Contaminated reagents contaminated

If differentiation between contaminating and endogenous DNA is possible (only possible when each product is cloned separately), continue or repeat the whole extraction with newly prepared solutions (repetition is recommended)

Cross-contamination during procedure

\section{ANTICIPATED RESULTS}

We extracted DNA from a number of cave bear and mammoth samples (Supplementary Table 1) using this protocol. Samples ranged in weight from 295 to $580 \mathrm{mg}$. We amplified mitochondrial products from the cave bear samples ${ }^{12}$ and nuclear products from the mammoth samples ${ }^{17}$ using regular ${ }^{16}$ or multiplex PCR ${ }^{21}$. Although not every PCR was successful in every attempt, 13 out of 17 cave bear samples gave positive mitochondrial PCR products in at least one trial using various dilutions of the extracts. Using mammoth samples and primers amplifying very short fragments of the nuclear MC1R gene, four out of six samples gave positive results in at least one trial using various dilutions (see Supplementary Table 1).

There seems to be no noticeable difference in the efficiency of this protocol between caves and open sites or between the different types of samples, as the majority of the PCR attempts were successful. 
Note: Supplementary information is available via the HTML version of this article.

ACKNOWLEDGMENTS We thank the members of the MPI EVA ancient DNA groups and Holger Römpler for discussion. This work was funded by the Max Planck Society.

COMPETING INTERESTS STATEMENT The authors declare no competing financial interests.

Published online at http://www.natureprotocols.com

Reprints and permissions information is available online at http://npg.nature.com/ reprintsandpermissions

1. Noonan, J.P. et al. Genomic sequencing of Pleistocene cave bears. Science 309, 597-599 (2005).

2. Noonan, J.P. et al. Sequencing and analysis of Neanderthal genomic DNA. Science 314, 1113-1118 (2006).

3. Margulies, M. et al. Genome sequencing in microfabricated high-density picolitre reactors. Nature 437, 376-380 (2005).

4. Poinar, H.N. et al. Metagenomics to paleogenomics: large-scale sequencing of mammoth DNA. Science 311, 392-394 (2006).

5. Green, R.E. et al. Analysis of one million base pairs of Neanderthal DNA. Nature 444, 330-336 (2006).

6. Rogaev, E.I. et al. Complete mitochondrial genome and phylogeny of Pleistocene mammoth Mammuthus primigenius. PLoS Biol. 4, e73 (2006).

7. Geigl, E.-M. On the circumstances surrounding the preservation and analysis of very old DNA. Archaeometry 44, 337-342 (2002).

8. Pääbo, S. Ancient DNA: extraction, characterization, molecular cloning, and enzymatic amplification. Proc. Natl. Acad. Sci. USA 86, 1939-1943 (1989).

9. Höss, M., Dilling, A., Currant, A. \& Pääblo, S. Molecular phylogeny of the extinct groundsloth Mylodon darwinii. Proc. Natl. Acad. Sci. USA 93, 181-185 (1996).

10. Hofreiter, M., Jaenicke, V., Serre, D., Haeseler Av, A. \& Pääbo, S. DNA sequences from multiple amplifications reveal artifacts induced by cytosine deamination in ancient DNA. Nucleic Acids Res. 29, $4793-4799$ (2001).

11. Hansen, A.J. et al. Crosslinks rather than strand breaks determine access to ancient DNA sequences from frozen sediments. Genetics 173, 1175-1179 (2006).

12. Rohland, N. \& Hofreiter, M. Comparison and optimization of ancient DNA extraction. Biotechniques 42, 343-352 (2007).

13. Höss, M. \& Pääbo, S. DNA extraction from Pleistocene bones by a silica-based purification method. Nucleic Acids Res. 21, 3913-3914 (1993).

14. Hänni, C., Brousseau, T., Laudet, V. \& Stehelin, D. Isopropanol precipitation removes PCR inhibitors from ancient bone extracts. Nucleic Acids Res. 23, 881-882 (1995).

15. Kalmar, T., Bachrati, C.Z., Marcsik, A. \& Rasko, I. A simple and efficient method for PCR amplifiable DNA extraction from ancient bones. Nucleic Acids Res. 28, E67 (2000).

16. Hofreiter, M. et al. Evidence for reproductive isolation between cave bear populations. Curr. Biol. 14, 40-43 (2004).

17. Rompler, H. et al. Nuclear gene indicates coat-color polymorphism in mammoths. Science 313, 62 (2006).
18. Hofreiter, M., Serre, D., Poinar, H.N., Kuch, M. \& Pääbo, S. Ancient DNA. Nat. Rev. Genet. 2, 353-359 (2001).

19. Pääbo, S. et al. Genetic analyses from ancient DNA. Annu. Rev. Genet. 38 645-679 (2004)

20. Willerslev, E. \& Cooper, A. Ancient DNA. Proc. Biol. Sci. 272, 3-16 (2005).

21. Roempler, H. et al. Multiplex amplification of ancient DNA. Nat. Protoc. 1, 720-728 (2006).

22. Leonard, J.A., Wayne, R.K. \& Cooper, A. Population genetics of ice age brown bears. Proc. Natl. Acad. Sci. USA 97, 1651-1654 (2000).

23. Haak, W. et al. Ancient DNA from the first European farmers in 7500 -year-old Neolithic sites. Science 310, 1016-1018 (2005).

24. Shapiro, B. et al. Rise and fall of the Beringian steppe bison. Science 306, 1561-1565 (2004).

25. Serre, D. et al. No evidence of neandertal mtDNA contribution to early modern humans. Plos Biol. 2, 313-317 (2004).

26. Orlando, L. et al. Revisiting Neanderthal diversity with a 100,000 year old mtDNA sequence. Curr. Biol. 16, R400-R402 (2006).

27. Caramelli, D. et al. A highly divergent mtDNA sequence in a Neanderthal individual from Italy. Curr. Biol. 16, R630-R632 (2006).

28. Iudica, C.A., Whitten, W.M. \& Williams, N.H. Small bones from dried mammal museum specimens as a reliable source of DNA. Biotechniques 30, 732-736 (2001)

29. Vigilant, L., Hofreiter, M., Siedel, H. \& Boesch, C. Paternity and relatedness in wild chimpanzee communities. Proc. Natl. Acad. Sci. USA 98, 12890-12895 (2001).

30. Schander, C. \& Halanych, K.M. DNA, PCR and formalinized animal tissue-a short review and protocols. Org. Divers. Evol. 3, 195-205 (2003).

31. Poinar, H.N. et al. Molecular coproscopy: dung and diet of the extinct ground sloth Nothrotheriops shastensis. Science 281, 402-406 (1998).

32. Reynolds, M.M. \& Williams, C.G. Extracting DNA from submerged pine wood. Genome 47, 994-997 (2004).

33. Ou, C.Y., Moore, J.L. \& Schochetman, G. Use of UV irradiation to reduce false positivity in polymerase chain reaction. Biotechniques 10, 442, 444, 446 (1991).

34. Gilbert, M.T.P., Hansen, A.J., Willerslev, E., Turner-Walker, G. \& Collins, M. Insights into the processes behind the contamination of degraded human teeth and bone samples with exogenous sources of DNA. Int. J. Osteoarchaeol. 16, 156-164 (2006).

35. Sambrook, J., Fritsch, E.F. \& Maniatis, T. Molecular Cloning: A Laboratory Manual (Cold Spring Harbor Laboratory Press, Cold Spring Harbor, New York, 1989).

36. Tuma, R.S. et al. Characterization of SYBR Gold nucleic acid gel stain: a dye optimized for use with 300-nm ultraviolet transilluminators. Anal. Biochem. 268 , 278-288 (1999).

37. Singer, V.L., Jones, L.J., Yue, S.T. \& Haugland, R.P. Characterization of PicoGreen reagent and development of a fluorescence-based solution assay for double-stranded DNA quantitation. Anal. Biochem. 249, 228-238 (1997)

38. Heid, C.A., Stevens, J., Livak, K.J. \& Williams, P.M. Real time quantitative PCR. Genome Res. 6, 986-994 (1996). 